\section{Using a concentrate of phenols obtained from olive vegetation water to preserve chilled food: two case studies}

\author{
Luca Fasolato, ${ }^{1}$ Barbara Cardazzo, ${ }^{1}$ \\ Stefania Balzan, ${ }^{1}$ Lisa Carraro, ${ }^{1}$ \\ Nadia Andrea Andreani, ${ }^{1}$ \\ Agnese Taticchi, ${ }^{2}$ Enrico Novelli' \\ 'Department of Comparative Biomedicine \\ and Food Science, University of Padua, \\ Legnaro (PD); ${ }^{2}$ Department of \\ Agricultural, Food and Environmental \\ Sciences, University of Perugia, Perugia, \\ Italy
}

\section{Abstract}

Phenols are plant metabolites characterised by several interesting bioactive properties such as antioxidant and bactericidal activities. In this study the application of a phenols concentrate (PC) from olive vegetation water to two different fresh products - gilt-head seabream (Sparus aurata) and chicken breast - was described. Products were treated in a bath of PC (22 g/L; chicken breast) or sprayed with two different solutions (L1:0.75 and L2:1.5 $\mathrm{mg} / \mathrm{mL}$; seabream) and then stored under refrigeration conditions. The shelf life was monitored through microbiological analyses quality index method for seabream and a specific sensory index for raw breast. The secondary products of lipid-peroxidation of the chicken breast were determined using the thiobarbituric acid reactive substances (TBARs) test on cooked samples. Multivariate statistical techniques were adopted to investigate the impact of phenols and microbiological data were fitted by DMfit software. In seabream, the levels of PC did not highlight any significant difference on microbiological and sensory features. DMfit models suggested an effect only on $\mathrm{H}_{2} \mathrm{~S}$ producing bacteria with an increased lag phase compared to the control samples (C: $87 \mathrm{~h}$ vs L2: $136 \mathrm{~h}$ ). The results on chicken breast showed that the PC bath clearly modified the growth of Pseudomonas and Enterobacteriaceae. The phenol dipping was effective in limiting lipid-peroxidation (TBARs) after cooking. Treated samples disclosed an increase of shelf life of 2 days. These could be considered as preliminary findings suggesting the use of this concentrate as preservative in some fresh products.

\section{Introduction}

The recycling of compounds from waste can reduce the pollution and at the same time the bioactive substances could be used as ingredients in food. Moreover, the use of plant extracts is considered a new strategy in food safety management and the application of these molecules is favourably accepted by the consumer (David et al., 2013). A real impact of plant extracts is related to the specific interactions with food matrices that can reduce the bactericidal effect of natural compounds or can limit bioactive properties (Klančnik et al., 2011). The storage tests could provide a wide range of information on the applicability of new substances and the final impact on microbial populations. Moreover, the useful doses for a real application of novel ingredients/ treatments are also linked to organoleptic traits and final sensory acceptance. Previous results in meat models revealed that the use of extracts from the waste waters of olive oil pomace and olive mill wastewater (OMW) reduced the genesis of lipid oxidation markers such as thiobarbituric acid reactive substances (TBARs) in ground meat and meat products (Galanakis et al., 2011; Novelli et al., 2014). These effects on lipid quality maintenance were related to the scavenger activity of some compounds (e.g. hydroxytyrosol and oleuropein); moreover an additional improvement of meat quality was described by the color attributes (Galanakis et al., 2011). Preliminary findings on bactericidal effects of purified phenols extract obtained from the vegetation water of the oil mill (PEOW) on several food-borne strains (spoilage bacteria, food-borne pathogens and starter cultures) suggested a clear inhibition of growth and survival of Gram positive bacteria (e.g. S. aureus and L. monocytogens) (Fasolato et al., 2015). Taking this information into account, the use of extracts or concentrates from OMW could be used to improve microbial stability, food quality and shelf life of fresh products. The aim of this study was to describe some preliminary results on the effects of a phenolic concentrate (PC) derived from OMW on the shelf life of two different food matrices: a brackish water finfish Sparus aurata (gilt-head seabream) and chicken breast. These two food models were examined for several microbial targets and lipid oxidation (chicken breast) in comparison with their respective sensory scales [quality index methods (QIM) and sensory index (SI)] during the refrigeration.

\section{Materials and Methods}

\section{Sampling and phenolic concentrate treatments}

The PC is a solution with a total concentra-
Luca Fasolato, Department of Comparative Biomedicine and Food Science, University of Padua, viale dell'Università 16,35020 Legnaro (PD), Italy.

Tel: +39.049.8272965 - Fax: +39.049 .8272604 .

E-mail: luca.fasolato@unipd.it

Key words: Phenols; Fresh food; Olive vegetation water; Shelf life.

Received for publication: 28 November 2015

Revision received: 2 February 2016.

Accepted for publication: 2 February 2016.

This work is licensed under a Creative Commons Attribution-NonCommercial 4.0 International License (CC BY-NC 4.0).

(C) Copyright L. Fasolato et al., 2016

Licensee PAGEPress, Italy

Italian Journal of Food Safety 2016; 5:5651

doi:10.4081/ijfs.2016.5651

tion of phenols of about $22 \mathrm{~g} / \mathrm{kg}$ whose main compounds are oleuropein aglicone $(3,4$ DHPEA-EDA; $13.6 \mathrm{~g} / \mathrm{kg})$, hydroxytyrosol $(3,4$ DHPEA; $2.9 \mathrm{~g} / \mathrm{kg}$ ), tyrosol (p-HPEA; $0.4 \mathrm{~g} / \mathrm{kg}$ ) and verbascoside $(5.1 \mathrm{~g} / \mathrm{kg})$. Two different experiments were carried out in order to evaluate the feasibility of PC treatment on fresh products.

\section{Gilt-head seabream}

Gilt-head seabream samples (Sparus aurata, $\mathrm{n}=34$ ) were obtained from an extensive rearing system of Valle Nova in northeast Italy during the winter season. The fish were immediately slaughtered in ice bath and then refrigerated. Samples were sprayed with two different concentrations of $\mathrm{PC}$ ( $\mathrm{L} 1=0.75 \mathrm{mg} / \mathrm{L}$ and $\mathrm{L} 2=1.5 \mathrm{mg} / \mathrm{L}$ ); both skin and gills were treated. Each fish was packaged using a rigid tray and a PVC film. The tested doses were selected according to preliminary observations of a similar extract (PEOW) on other food matrices (such as raw or fermented sausages) (Novelli et al., 2015). These models highlighted significant bioactive effects (e.g. antioxidant and bactericidal activities) of phenolic compounds. According to preliminary experiments on seabream (data not showed), these treatments did not markedly change sensory traits.

The trays were then displayed in a refrigerated cabinet (Costan SpA, Belluno, Italy) for 14 days and randomly sampled at 1, 3, 5, 8, 12 and 14 days from the packaging date. As control of initial Time, 4 fish were sampled before any manipulation. The storage settings have been designed with the intent to mimic the refrigeration condition during the sale (packaging and exposure to light). Exposure to light (OSRAM L36W/76-1) was fixed from 8:00 to 20:00 at an average temperature of $4^{\circ} \mathrm{C} \pm 1$. 


\section{Chicken breast}

Broilers breast were sampled from the same lot in a slaughterhouse of northeast Italy. The chicken breasts $(n=8)$ were dipped in a bath with the PC ( $22 \mathrm{~g} / \mathrm{kg}$ of total phenols fraction) while $n=8$ samples were considered as control. After treatment (1 min), the samples were packaged in the same manner as described for gilt-head seabream and then analysed during their shelf life at 1, 4, 7 and 10 days. Two independent replication of the bath were applied. The samples were randomly disposed in the same condition described for gilt-head seabream.

\section{Sensory analyses}

The sensory analyses were conducted by 5 trained panellists on gilt-head seabream samples according to the QIM schema proposed by Huidobro et al. (2000). The panellists did not know in advance the treatments of samples; moreover, two additional odour descriptors (perception of anomalous odours on gills and fish surface) were considered. PC possesses a characteristic smell of olive oil. These descriptors were introduced to verify the panelists' ability to discriminate among treatments. Instead, a demerit score SI proposed by Raab et al. (2008) was adopted for the sensory examination of broiler breasts. This index resumes the colour, texture and odour aspects of breast with a spoilage threshold of 1.8 .

\section{Microbiological analyses}

The samples were monitored according to several microbiological analyses in order to highlight changes in microflora. Two different sampling methods were applied. The gilt-head seabream were analysed for the microbial surface microflora: a delimitated area was swabbed $\left(25 \mathrm{~cm}^{2}\right)$ with sterile cotton swabs and spread in $10 \mathrm{~mL}$ of Maximum Recovery Diluent $(\mathrm{MRD}=8 \mathrm{~g}$ of $\mathrm{NaCl} / \mathrm{L}, 1 \mathrm{~g}$ of bacteriological peptone/L) followed by serial dilutions. The gills were cut with sterile scissors and a $9 \times$ volume of MRD was added for the subsequent serial dilutions. For the chicken breast, $25 \mathrm{~g}$ of sample was homogenised in a sterile stomacher bag with $225 \mathrm{~mL}$ of buffered peptone water (BPW) followed by serial 10 -fold dilutions. The microbial targets analysed were: the total viable count (TVC) and total psycrotrophic count (TPC) on Plate Count Agar (Biokar Diagnostics, Beauvais, France) incubated respectively at $30^{\circ} \mathrm{C}$ for $72 \mathrm{~h}$ and $4^{\circ} \mathrm{C}$ for 10 days respectively; Enterobacteriaceae on Violet Red Bile Glucose Agar (Biokar Diagnostics) incubated at $37^{\circ} \mathrm{C} \pm 1^{\circ} \mathrm{C}$ for $24 \pm 2$ $\mathrm{h}$, lactic acid bacteria on MRSA agar (de Man, Rogosa and Sharpe agar; Biokar Diagnostics) incubated in anaerobic conditions for $48 \mathrm{~h}$ at $30^{\circ} \mathrm{C}$, Pseudomonas spp. in Pseudomonas Agar Base supplemented with cetrimide, fucidine, cephaloridine for $48 \mathrm{~h}$ at $25^{\circ} \mathrm{C}$ (Oxoid Ltd,
Basingstoke, Hampshire, UK), selective counts of $\mathrm{H}_{2} \mathrm{~S}$-producing bacteria (putative Shewanella spp.) at $25^{\circ} \mathrm{C}$ for $48 \mathrm{~h}$ and Oxytetracycline Glucose yeast extract agar (OGYE; Oxoid) was used for yeast and mould counts $\left(25^{\circ} \mathrm{C}, 3-5\right.$ days). Results were reported as $\log _{10}$ colony forming units (CFU)/g or $\mathrm{cm}^{2}$.

\section{Chemical analyses}

The secondary products of lipid-peroxidation of the chicken breast were determined using the TBARs test on cooked samples. Starting from the supposition that the effect of the phenols was limited to the surface of the breast, the samples were cooked in water bath at $80^{\circ} \mathrm{C}$ for 30 min with two different manners of preparation. For each breast sample two sections (subsamples) of around $50 \mathrm{~g}$ each one were dissected. One was finely grounded and $25 \mathrm{~g}$ was used to fill a plastic round shape of 60 mm diameter and $10 \mathrm{~mm}$ height that was vacuum packaged together with the second subsample as such. The subsamples were cooked for $30 \mathrm{~min}$ in a water bath set at $80^{\circ} \mathrm{C}$. After cooking, the subsamples were chilled under tap water and stored at $4^{\circ} \mathrm{C}$ for $72 \mathrm{~h}$ before analysis. The surface of the subsample cooked as such was trimmed for a thickness of $3 \mathrm{~mm}$ that was homogenised in a mortar using a pestle in porcelain. From each subsamples $2 \mathrm{~g}$ accurately weighed were then taken and processed according to the method of Botsoglou et al. (1994), modified as follows. In a centrifuge tube, $8 \mathrm{~mL}$ of an aqueous solution of $5 \%$ trichloroacetic acid and $5 \mathrm{~mL}$ of n-hexane with $0.008 \%$ Buthylhydroxytoluene (antioxidant agent) were added to the meat sample. After homogenisation with an Ultraturrax (T25 Basic; Ika Werke, Staufen im Breisgau, Germany) for $30 \mathrm{sec}$ at high speed, the sample was centrifuged for $3 \mathrm{~min}$ at $3000 \mathrm{~g}$ at $4^{\circ} \mathrm{C}$ (Eppendorf 5810R; Eppendorf, Hamburg, Germany) and the supernatant was removed. To eliminate the residual solid component, the sample was filtered through paper for a rapid filtration. An aliquot of the filtrate $(2.5 \mathrm{~mL})$ was added to $2.5 \mathrm{~mL}$ of a solution of $0.02 \mathrm{M}$ thiobarbituric acid (TBA) and incubated for 35 min at $95^{\circ} \mathrm{C}$ in a thermostated bath (Julabo ED-13; Seelbach, Baden-Württemberg, Germany). After cooling, the absorbance of the chromatic adduct was read by means of a spectrophotometer Mod. 7800 Jasco UV/NIS (Jasco, Oklahoma City, OK, USA) set at a wavelength of $532 \mathrm{~nm}$. The results were expressed as $\mathrm{mg}$ malonaldehyde (MDA)/kg meat using a calibration curve to convert the absorbance in weight of MDA.

\section{Statistical analysis}

Two-way permutational multivariate analysis of variance (PERMANOVA) test was performed (Anderson, 2001) to highlight the effects of the fixed factors Phenol treatments,
Storage time and their interaction. In case of significant effects, a posteriori pair-wise comparisons were determined. In order to investigate the relationship among sensory features and the microbial targets a distance based redundancy analysis (dbRDA) and a distancebased multivariate analysis for a linear model (DISTLM) were performed (Anderson, 2003; Clarke and Gorley, 2006). The microbial counts variable profiles were studied also by means of a principal component analysis (PCA) and a subsequent stepwise linear discriminant analysis (LDA) one in order to discover the possibility to use the Component Scores for the prediction of time and treatment of samples. For chemical analysis, a one-way ANOVA test and the Tukey $b$ a posteriori test were used to determine significant differences $(\mathrm{P} \leq 0.05$, $\mathrm{P}<0.01, \mathrm{P}<0.001)$ within the factors treatment and storage time. These analyses were performed using the IBM $^{\circledR}$ SPSS $^{\circledR}$ Statistics 20 Core System. The raw data were investigated with the DMFit programme in order to evaluate the effect of treatments on growth curves parameters.

\section{Results and Discussion}

\section{Gilt-head seabream}

The PERMANOVA analysis of the microbial count profiles of both skin and gills did not reveal any statistical change on the gilt-head seabream samples treated with phenol concentrate. The two doses of treatment did not influence the composition of microbiota analysed by plate count methods. The only statistical differences were related to the time of shelf life $(\mathrm{P}=0.0001)$ and the matrices considered (gill vs skin; $\mathrm{P}=0.0015)$. These results highlighted that the microbial counts changed during the storage period and that the behaviors of bacteria on gill and skin were different. The LDA showed similar results; for instance, no canonical discriminant functions were determined for the classification of samples according treatments (polyphenols $v s$ control). LDA models were applied to discover the microbiological features able to predict the storage time of gilt-head seabream samples. Two canonical discriminant functions were suitable for the classification of skin samples according to the storage time (Figure 1A). The use of principal components PC1 and PC3 accounted the 79.4\% of original grouped cases. TPC and TVC were selected as main explanatory variables. On the other hand, the features of gills did not allow a clear classification of samples (less than 50\%) suggesting that this matrix is not suitable for time prediction. Interestingly, this approach did not select the classical specific spoilage organisms (SSO) involved in the fish deterioration such as Pseudomonas and the $\mathrm{H}_{2} \mathrm{~S}$-pro- 
ducing bacteria (mainly Shewanella spp.) particularly in Sparus aurata (Giuffrida et al., 2008). In order to confirm these results a $\mathrm{dbRDA}$ and DSTLM were conducted on the sensory data set of QIM in order to evaluate the microbial targets that affected the sensory trait variability. The matrix of 8 sensory descriptors of QIM (Huidobro et al., 2000) was superimposed to the vectors of microbial classes (Figure 1B). Once again, these analyses selected the TPC $(\mathrm{P}=0.0002)$ as descriptor of the total variation of organoleptic features. This integrated statistical approach allowed to discover the contribution of each microbial features along to the shelf life of fish suggesting psycrotrophic bacteria as descriptors of spoilage.

DMfit models are resumed in the Figure 2AC. The use of the software permitted to fit the raw data into primary models in order to extrapolate some additional information. The complete Baranyi and Roberts model showed the best fit for all reported results [QIM R2: 0.97 , standard error (SE) of Fit 0.6; TPC $\mathrm{R}^{2}$ : 0.97, SE of Fit 0.4]. The QIM showed that gilthead seabream samples were rejected at $322 \mathrm{~h}$ considering a threshold of 12 score as proposed by Giuffrida et al. (2008). The behaviors of TPC presented a Lag phase of $89 \mathrm{~h}$ and a maximum rate of $0.0575 \mathrm{Log}_{10}\left(\mathrm{CFU} / \mathrm{cm}^{2} / \mathrm{h}\right)$ with a plateau of $6.8 \log _{10}\left(\mathrm{CFU} / \mathrm{cm}^{2}\right)$ at $235 \mathrm{~h}$. Among the microbial targets investigated, only the $\mathrm{H}_{2} \mathrm{~S}$-producing bacteria seemed to display differences in the growth behaviors according to the spray treatment with phenolic concentrate (Figure 2C). The putative Shewanella spp. showed a period of Lag phase of around $136 \mathrm{~h}$ in L2 samples compared to the control that accounted $87 \mathrm{~h}$ of latent phase. This suggests a different period of adaptation to the environment probably due to the presence of the higher level of phenolic substances. However, the bactericidal effects against $\mathrm{H}_{2} \mathrm{~S}$ - producing bacteria need to be explored also in vitro tests, in order to understand the potential inhibition of the concentrate.

According to the preliminary results, it is possible to assume that the phenol concentrate did not affect the shelf life and freshness of fish sample. The levels of concentrate did not markedly change the sensory perception (e.g. odour or colour) of the products. For instance, the panelists were able to classify the $70 \%$ samples (polyphenols $v s$ control) due to the smells of the skin surface. This suggested that the tested doses modified the odor without any other favorable influence on fish preservation. The modality of administration seemed not to be appropriated for the conservation of whole fish stored under aerobic conditions. Probably, the modality of administration (e.g spray $v s$ bath) or the doses were ineffective against the common microbiota of gilt-head seabream. Other studies on the use of phenolic compounds showed a clear effect on fish products, but the substances applied (e.g. rosemary extract) or the tested fish-product (fillet and not whole fish) did not allowed a clear comparison of the results (Gao et al., 2014). Probably, the use of ice enriched with phenols could enhance the effect of these substances as proposed by Bensid et al. (2014) on anchovy (Engraulis encrasicholus), where solutions of thyme, oregano and clove extracts seemed to modify some microbial targets.
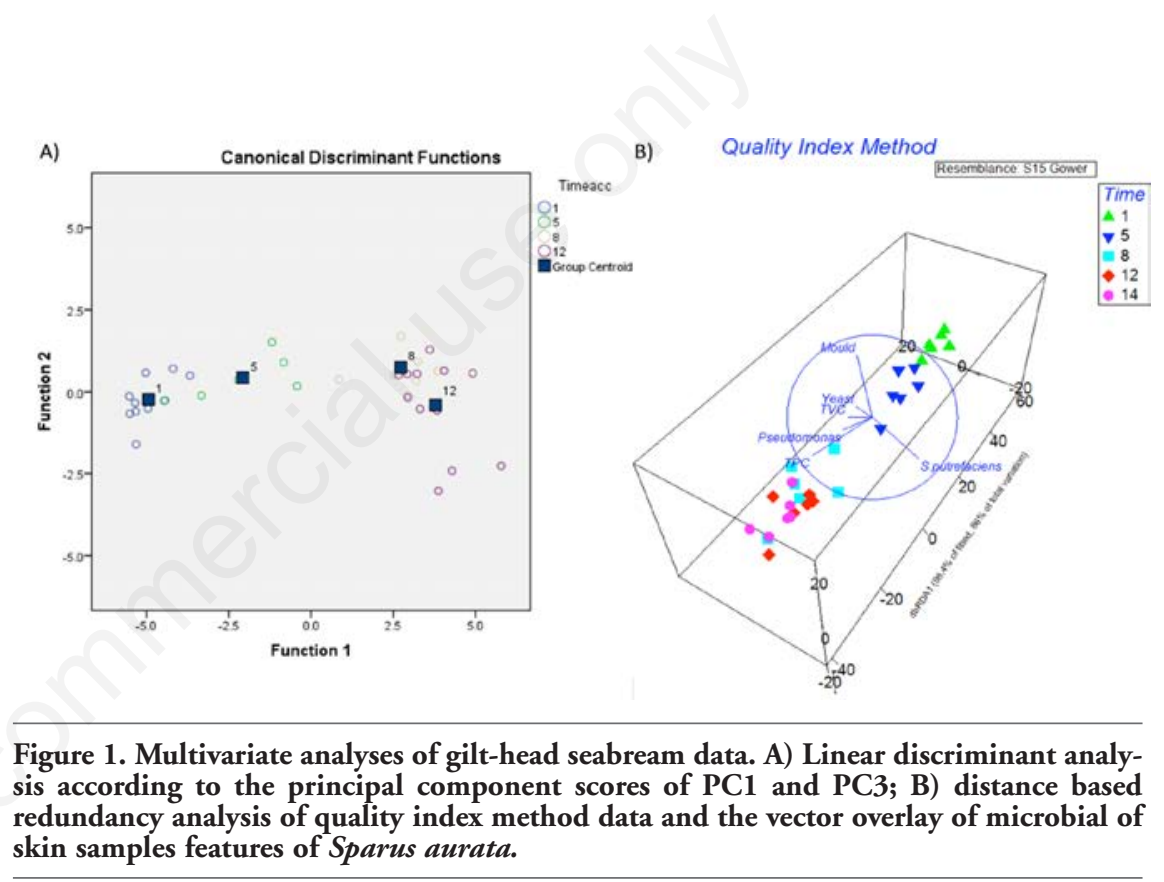

Figure 1. Multivariate analyses of gilt-head seabream data. A) Linear discriminant analysis according to the principal component scores of PC1 and PC3; B) distance based redundancy analysis of quality index method data and the vector overlay of microbial of skin samples features of Sparus aurata.
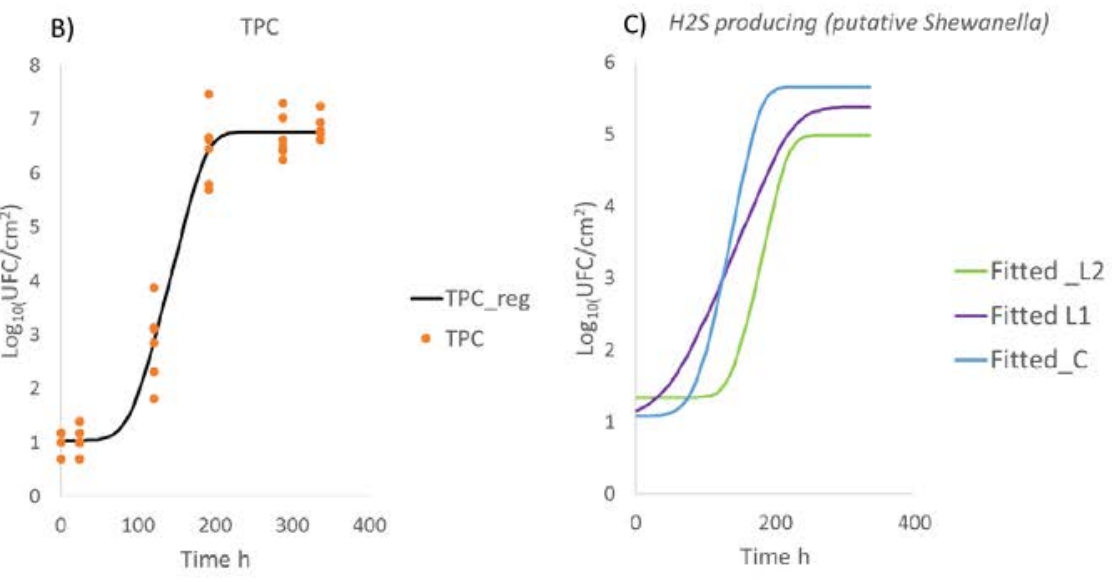

Figure 2. DMfit results of complete Baranyi and Roberts models. A) Quality index methods data and threshold of rejection; B) total psycrotrophic count; C) $\mathrm{H}_{2} \mathrm{~S}$-producing bacteria (putative Shewanella) according to the phenolic concentrate doses. 


\section{Chicken breast}

The PC influenced the microbial counts and quality traits of poultry meat (Figure 3). PERMANOVA results highlighted a clear effect of $\mathrm{PC}(\mathrm{P}=0.0042)$ and storage time $(\mathrm{P}=0.0002)$, but not of their interaction. For instance, the Enterobacteriaceae and Pseudomonas showed a delay in growth. Enterobacteriaceae showed around $4 \log _{10} \mathrm{CFU} / \mathrm{g}$ of difference between control and treated samples at 7 days of storage
(Figure 3C). The dbRDA and DISTLM of SI matrix compared to the microbial features clearly selected the Pseudomonas $(\mathrm{P}=0.001)$ as predictor (Figure 3A). Pseudomonas is a SSO of poultry meat and is widely used to define the

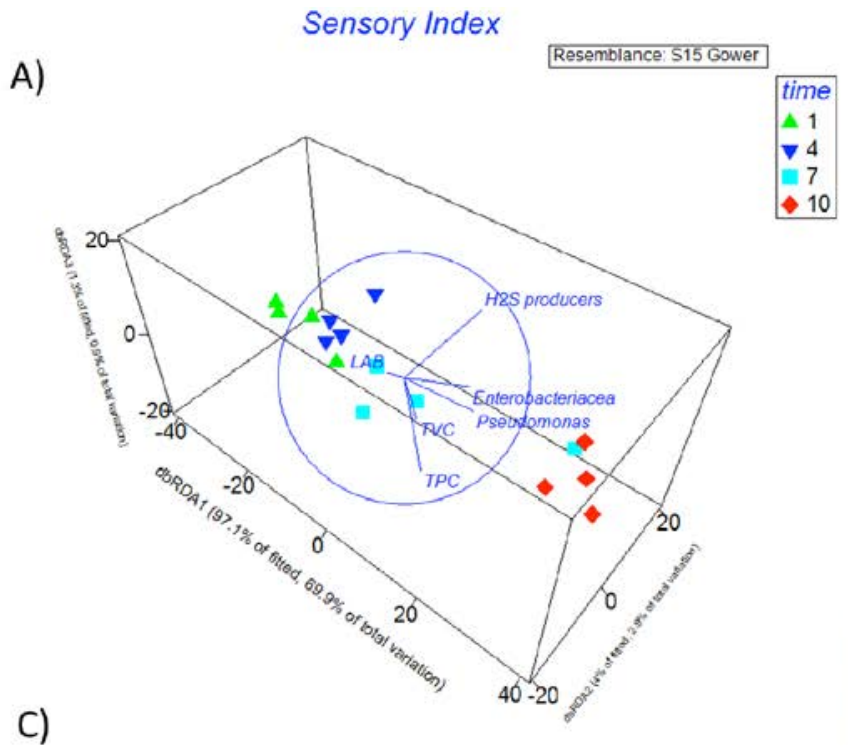

Enterobacteriaceae

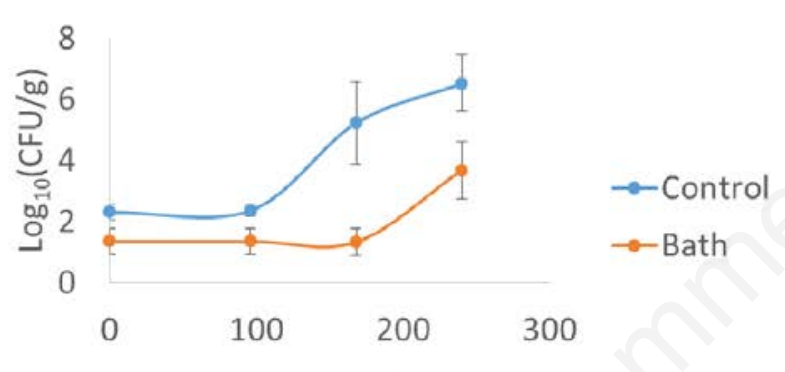

Time h

D)

B)

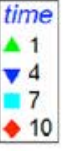
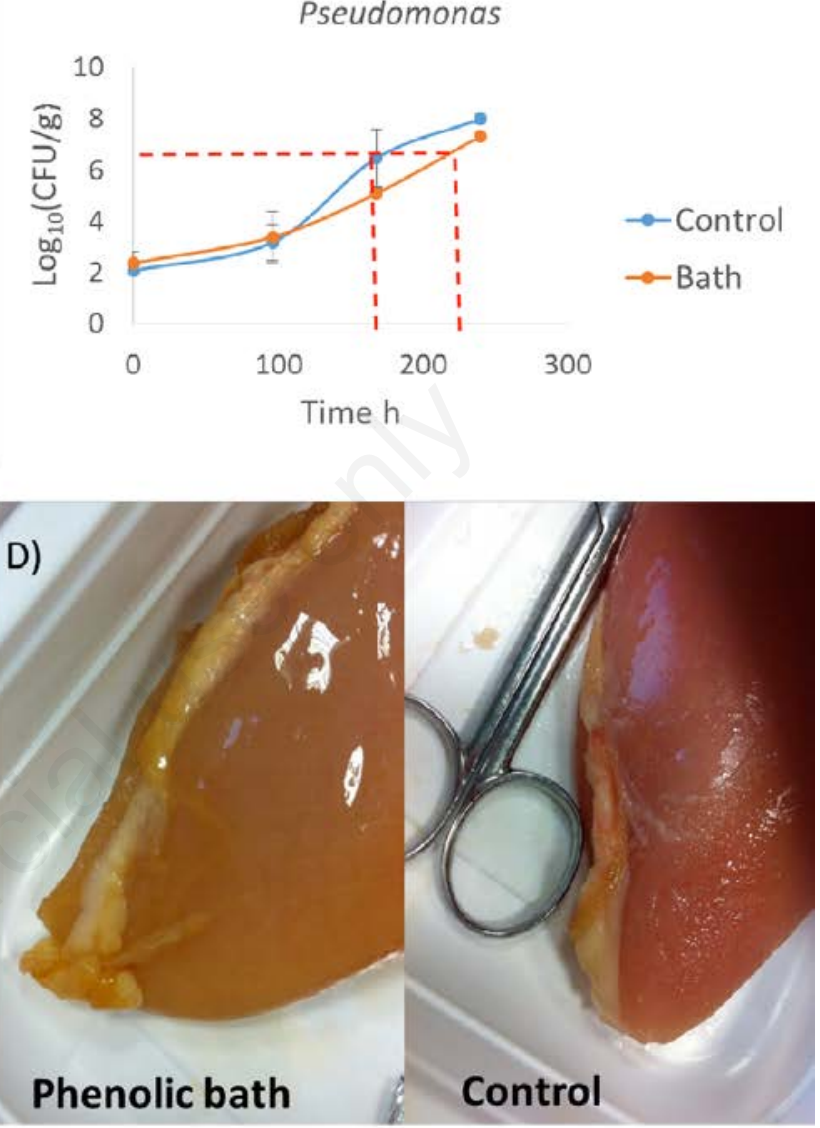

Figure 3. Results of phenolic bath on breast chicken. A) Distance based redundancy analysis of sensory index and microbial features; B) Pseudomonas $\log _{10}$ colony forming units (CFU)/g and the threshold of rejection; C) Enterobacteriaceae Log 10 CFU/g; D) colour changes of flesh surface.
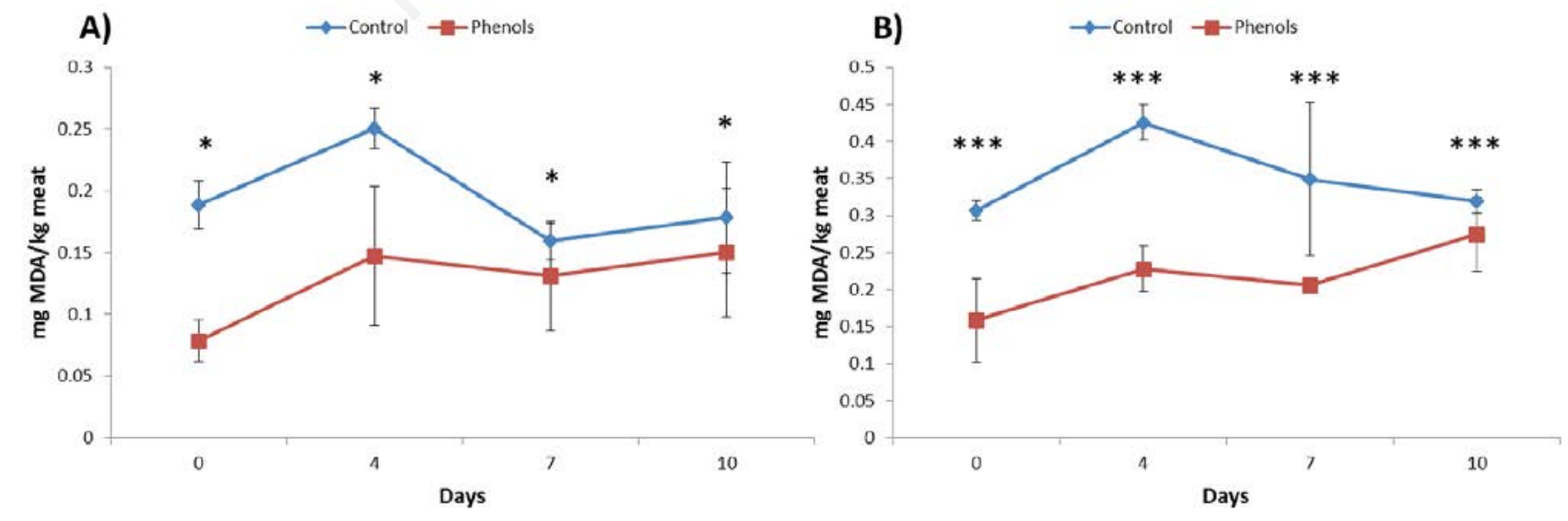

Figure 4. Thiobarbituric acid reactive substances value ( $\mathrm{mg} \mathrm{MDA} / \mathrm{kg})$ in meat of chicken breast cooked at $80^{\circ} \mathrm{C}$ for $30 \mathrm{~min}$ in a water bath and stored at $4^{\circ} \mathrm{C}$ for $72 \mathrm{~h}$ before analysis. A) minced sample; B) sample cooked as such. Values are expressed as mean \pm standard deviation. ${ }^{*} \mathrm{P}<0.05,{ }^{* * *} \mathrm{P}<0.001$. 
acceptable threshold before alteration (Raab et al., 2008). Considering the threshold proposed by Raab et al. (2008) equal to $7.3 \log _{10} \mathrm{CFU} / \mathrm{g}$, we could assume that the control samples showed a shelf life of $173 \mathrm{~h}$ (around 8 days) compared to treated samples that showed the overt spoilage at 10 days (Figure $3 \mathrm{~B}$ ). The PC did not affect the SI, probably because this index considered only 3 main descriptors (color, texture and odor) with a 3 demerit point scale. However, the color of breast surface clearly changes after bath (Figure 3D). This yellowish color on fat and muscle remained for all the shelf life, while the odor maintained the initial score values during the first 7 days suggesting a certain influence on this descriptor.

In Figure 4 the results of the TBARs test on chicken breast after cooking and storage for three days at $4^{\circ} \mathrm{C}$ can be seen. In the case of the sample minced before the cooking process (A) the difference of the means at each sampling time was significant at $\mathrm{P}<0.05$, whereas the difference was more evident $(\mathrm{P}<0.001)$ when just the outside thickness of the breast was considered for the analysis (B). In other words, it means that according to the first approach there was a dilution of the most oxidated external thickness. However, apart from the analytical approach adopted, it was clear the efficacy of the phenols, added by dipping, in the protection of the lipid fraction from the oxidative action inducted, first by the exposition to fluorescent light for ten days then by the heat stress played by cooking. Phenols extracted from Echinacea angustifolia and mixed with chicken meat were able to contrast the progress of lipid oxidation during ten days of storage at $4{ }^{\circ} \mathrm{C}$ (Gallo et al., 2012). Mixtures of oregano plus sage and oregano plus sage plus honey added to the poultry meat were equally effective in limiting lipid peroxidation after cooking and storage at $4^{\circ} \mathrm{C}$ for four days (Sampaio et al., 2012).

\section{Conclusions}

A similar experiment on breast chicken dipping with pomegranate extract showed a clear effect on chemical, microbial and sensory traits of meat (Vaithiyanathan et al., 2011).
Our data suggested that the bath with $\mathrm{PC}$ was an effective modality of treatment; however, the use of explorative storage trial is necessary for each different product tested. The phenolic concentrate interacted with the food matrices and this needs to be considered for further applications. Our data highlight that the potential use of this concentrate may enhance the shelf life of chicken breast of 2 days.

\section{References}

Anderson MJ, 2001. A new method for nonparametric multivariate analysis of variance. Austral Ecology 26:32-46.

Anderson MJ, 2003. DISTLM forward: a FORTRAN computer program to calculate a distance-based multivariate analysis for a linear model using forward selection. Department of Statistics, University of Auckland, New Zealand.

Bensid A, Ucar Y, Bendeddouche B, Ozogul F, 2014. Effect of the icing with thyme, oregano and clove extracts on quality parameters of gutted and beheaded anchovy (Engraulis encrasicolus). Food Chem 145:681-6.

Botsoglou NA, Fletouris DJ, Papageorgiou GE, Vassilopoulos VN, Mantis AJ, Trakatellis AG, 1994. Rapid, sensitive, and specific thiobarbituric acid method for measuring lipid-peroxidation in animal tissue, food, and feedstuff samples. J Agr Food Chem 42:1931-7.

Clarke KR, Gorley RN, 2006. PRIMER V6: user manual and tutorial. PRIMER-E Ltd, Plymouth, UK.

David JR, Steenson LR, Davidson PM, 2013. Expectations and applications of natural antimicrobials to foods. Food Prot Trends 33:241-50.

Fasolato L, Cardazzo B, Balzan S, Carraro L, Taticchi A, Montemurro F, Novelli E, 2015. Minimum bactericidal concentration of a phenols extract from oil vegetation water on spoilers, starters and food-borne bacteria. Ital J Food Safety 4:4519.

Galanakis CM, Barbier C, Tornberg E, 2011. Production and utilization of food additives from olive mill wastewater. Available from: www.icef11.org/content/papers/few/ FEW479.pdf

Gallo M, Ferracane R, Naviglio D, 2012. Antioxidant addition to prevent lipid and protein oxidation in chicken meat mixed with supercritical extracts of Echinacea angustifolia. J Supercrit Fluid 72:198-204.

Gao M, Feng L, Jiang T, Zhu J, Fu L, Yuan D, Li $\mathrm{J}, 2014$. The use of rosemary extract in combination with nisin to extend the shelf life of pompano (Trachinotus ovatus) fillet during chilled storage. Food Control 37:18.

Giuffrida A, Ziino G, Donato G, Giarratana F, Filiciotto F, Panebianco A, 2008. Spoilage bacteria and quality index method score in reared gilthead gilthead seabream. AIVI 2008:49-52.

Huidobro A, Pastor A, Tejada M, 2000. Quality index method developed for raw Gilthead Gilthead seabream (Sparus aurata). J Food Sci 7:1202-5.

Klančnik A, Piskernik S, Možina SS, Gašperlin L, Jeršek B, 2011. Investigation of some factors affecting the antibacterial activity of rosemary extracts in food models by a food microdilution method. Int J Food Sci Tech 46:413-20.

Novelli E, Fasolato L, Cardazzo B, Carraro L, Taticchi A, Balzan S, 2014. Addition of phenols compounds to meat dough intended for salami manufacture and its antioxidant effect. Ital J Food Safety 3:1704.

Raab V, Bruckner S, Beierle E, Kampmann Y, Petersen B, Kreyenschmidt J, 2008. Generic model for the prediction of remaining shelf life in support of cold chain management in pork and poultry supply chains. J Chain Network Sci 8:5973.

Sampaio GR, Saldanha T, Soares RAM, Torres EAFS, 2012. Effect of natural antioxidant combinations on lipid oxidation in cooked chicken meat during refrigerated storage. Food Chem 135:1383-90.

Vaithiyanathan S, Naveena BM, Muthukumar M, Girish PS, Kondaiah N, 2011. Effect of dipping in pomegranate (Punica granatum) fruit juice phenolic solution on the shelf life of chicken meat under refrigerated storage $\left(4^{\circ} \mathrm{C}\right)$. Meat Sci 88:409-14. 